\title{
Cell Proliferation is Influenced by Bulbectomy and Normalized by Imipramine Treatment in a Region-Specific Manner
}

\author{
Gerburg Keilhoff*,', Axel Becker², Gisela Grecksch'², Hans-Gert Bernstein ${ }^{3}$ and Gerald Wolf' \\ 'Institute of Medical Neurobiology, University of Magdeburg, Magdeburg, Germany; ${ }^{2}$ Institute of Pharmacology and Toxicology, University \\ of Magdeburg, Magdeburg, Germany; ${ }^{3}$ Department of Psychiatry, University of Magdeburg, Magdeburg, Germany
}

\begin{abstract}
Growing evidence indicates that alterations of neuroplasticity may contribute to the pathophysiology of depression. In contrast, various antidepressants increase adult hippocampal neurogenesis and block the effects of stress. These findings result in the 'neurogenesis hypothesis of depression'. The present study seeks to determine out whether cell proliferation is altered in the hippocampus, subventricular zone (SVZ), and basolateral amygdala of adult rats exposed to bilateral olfactory bulbectomy, another established model of depression and, if so, how imipramine effects bulbectomy-induced changes of cell genesis. Bulbectomy results in a significant reduction of cell proliferation in the hippocampus and SVZ, an effect that is normalized by subchronic doses of imipramine. Moreover, an increase in cell genesis in the basolateral amygdala, which is not affected by imipramine, is demonstrated. TUNEL staining indicates an enhanced apoptosis after bulbectomy in the SVZ that cannot be reduced by imipramine. Cell death rates in the hippocampus and amygdala are not affected by bulbectomy. The opposing effects of bulbectomy and imipramine treatment in the hippocampus and amygdala demonstrate that these structures of the limbic system, both integrated in emotional processing, react quite differently with regard to neuroplasticity. Further to this, we discuss a possible link between the pathogenesis of depression and changed neuronal plasticity in the SVZ. Neuropsychopharmacology (2006) 3 I, I |65- I 176. doi:I 0. I038/sj.npp. I 300924; published online 5 October 2005
\end{abstract}

Keywords: amygdala; bulbectomy; depression; hippocampus; rat; subventricular zone

\section{INTRODUCTION}

The presence of neural progenitor cells that give rise to new neurons in the adult brain of a variety of species, including humans, has been established definitively. Throughout life, neural stem cells continue to proliferate and produce neurons and glia in the hippocampal dentate gyrus and in the subventricular zone (SVZ) of the lateral ventricle (Schaffer and Gage, 2004). Immature neurons in the subgranular zone of the hippocampus migrate into the granule cell layer (Hastings and Gould, 1999), where they differentiate and appear to have morphological and physiological characteristics that are similar to adult granule cells (van Praag et al, 2002). Precursors of the anterior SVZ migrate through the rostral migratory stream (RMS) into the core of the olfactory bulb. Here, the young neurons leave the RMS and migrate into the granule and periglomerular layers, where they differentiate into interneurons (Kirschenbaum et al, 1999). Gliogenesis occurs

\footnotetext{
*Correspondence: Dr G Keilhoff, Institute of Medical Neurobiology, University of Magdeburg, Leipziger Strasse 44, Magdeburg D-39120, Germany, Tel: + 49 39| 67 |4368, Fax: + 49 39| 67 |4365,

E-mail: gerburg.keilhoff@medizin.uni-magdeburg.de

Received 25 April 2005; revised 16 August 2005; accepted 30 August 2005

Online publication: I September 2005 at http://www.acnp.org/ citations/Npp090 105050267/default.pdf
}

predominantly from the posterior SVZ (Zerlin et al, 2004). Recent evidence also indicates the existence of multipotent precursors in the RMS, and that these are capable of giving rise to oligodendrocytes and astrocytes (Gritti et al, 2002).

Multiple factors have been shown to regulate adult cell proliferation, and several findings in this field have had a large impact on basic and clinical research on depression (Kempermann and Kronenberg, 2003; Duman, 2004; Malberg, 2004; Sapolsky, 2004).

The notion that depression can arise from impaired hippocampal neurogenesis (Gould et al, 1997; Jacobs, 2002; Kempermann, 2002), and that an array of antidepressants work by stimulating neurogenesis (Malberg et al, 2000; Malberg and Duman, 2003; Castren, 2004), has led to an exciting hypothesis, referred to as the 'neurogenesis hypothesis of depression' (Duman, 2004; Sapolsky, 2004). In contrast, transcranial magnetic stimulation, an effective treatment for depression, does not alter rates of neurogenesis in rats (Czeh et al, 2002). To date, clinical studies investigating a link between depression and neurogenesis have, at best, only provided an indirect indication of a reduction in hippocampal volume in cases of depression. Manual segmentation protocols have established a decline in hippocampal volume associated with disorders that differ from depression, such as Alzheimer's disease (Ishii et al, 2005) and epilepsy (Bouix et al, 2005). Furthermore, recent studies have investigated changes in hippocampus volume 
in cognitively normal subjects; these studies have demonstrated reduced volume after coronary artery disease (Koschack and Irle, 2005), and in early adulthood in men, but not women (Bouix et al, 2005). Moreover, there are very few post-mortem histological studies addressing the question of hippocampal cell loss, and, to date, these have not detected any neuronal loss (Lucassen et al, 2001; Muller et al, 2001; Stockmeier et al, 2004). Further, and quite unexpectedly, in a rat ketamine model of schizophrenia, we were able to demonstrate an enhanced neurogenesis (Keilhoff et al, 2004), thus refuting the assumption that a reduced hippocampal volume is a clear indicator of diminished neurogenesis. These and other contradictions are reviewed by Henn and Vollmayr (2004a) under the heading 'Neurogenesis and Depression: Etiology or Epiphenomenon?'

To further contribute to this debate, we looked for cell proliferation after olfactory bulbectomy and at the effect of the antidepressant imipramine in this well-established animal model of depression. The olfactory bulbectomized rat has been proposed as a realistic animal model of depression because there is a significant overlap between the abnormalities in the rat (hyperactivity in the open-field test; enhanced nocturnal hyperactivity in a home cage activity monitor; deficits in memory, as shown by passive and active avoidance behavior and in the Morris maze; increased open arm entries in the elevated plus-maze; and changes in food motivated and conditioned taste aversion behavior, and in the endocrine, immune, and neurotransmitter systems) and the changes that have been reported to occur in patients with major depression (for a survey see: Kelly et al, 1997; Song and Leonard, 2005). Many of these changes have been shown to be attenuated by chronic (but not acute) antidepressant treatment, which indicates limitations of this model. However, the loss of olfaction alone is not the major factor contributing to the behavioral abnormalities, as peripherally induced anosmia does not cause the same behavioral changes. Together with the amygdala and hippocampus, the olfactory system forms a part of the limbic region that contributes to the emotional and memory components of rat behavior. These areas, the cortical-hippocampal-amygdala circuit, also appear to be dysfunctional in patients with major depression. Thus, the olfactory bulbectomized rat is not only a model for detecting antidepressant activity but also a model for exploring the inter-relationships between these systems integrated into the pathology of major depression.

Recently, we reported that olfactory bulbectomy in rats causes a syndrome of slowly developing, long-lasting behavioral, endocrine, and neurochemical abnormalities, which can be normalized by the tricyclic antidepressant imipramine (Grecksch et al, 1997), thus proving the validity of this model. Bulbectomized rats showed learning impairments in acquiring an active avoidance in the pole-jumping test. Moreover, it was shown that subchronic treatment with imipramine (3.75 mg/kg/day intraperitoneally (i.p.), starting 11 days before learning experiments) caused a significant improvement in learning performance. This result well correlates with neurochemical changes. The $B_{\max }$ value of $\left[{ }^{3} \mathrm{H}\right]$-paroxetine binding and the concentration of tryptophan hydroxylase apoenzyme were elevated in the frontal cortex of bulbectomized, but not in the frontal cortex of sham-operated control rats (Zhou et al, 1998). Subchronic treatment with imipramine reduced the elevated tryptophan hydroxylase apoenzyme levels.

As several reports have linked olfactory bulbectomy to changes in the amygdala and hippocampus (Richardson and Tiong, 1999, elevated density of $\beta$-adrenoceptors in the amygdala and hippocampus; Wrynn et al, 2000, decreased MRI signal in the amygdala, indicating an altered tissue volume, pronounced enlargement of the lateral ventricle with impaired hippocampal function as a consequence; Rutkoski et al, 2002, significant increase in neuropeptide $\mathrm{Y}$ expression in the amygdala; Watanabe et al, 2003, increased serotonin synthesis in the hippocampus), we selected the two brain areas for this study. Moreover, the hippocampus and amygdala besides the anterior cingulate and the prefrontal cortex are included into the key neural circuit of depression (Henn and Vollmayr, 2004b; Sapolsky, 2004). Damage to the amygdala produces diminished fear, hypoemotionality, decreased aggression, increased passivity, and deficits in memory related to emotion. Most significantly, activity in the amygdala is increased in mood disorders (Aggleton, 1993). Moreover, there have been reports of a significant increase in resting cerebral blood flow and glucose metabolism in the left amygdala of depressed patients with familial pure depressive disease (Drevets, 2000), and an abnormally elevated metabolism in the right amygdala in depressed patients with bipolar disorders (Ketter et al, 2001) was reported.

The SVZ was selected as a brain region that has intense neurogenesis and gliogenesis, even in adulthood, and which is apparently not involved in depression, but is affected by bulbectomy.

\section{MATERIALS AND METHODS}

\section{Animals}

All animal experiments were conducted in accordance with the requirements of the National Act on the Use of Experimental Animals in Germany, and approved by the 'Tierschutzkommission des Landes Sachsen-Anhalt'.

Male Wistar rats, 8 weeks old at the beginning of the experiments, were used (Shoe: Wist/Shoe, DIMED Schönwalde $\mathrm{GmbH}$ ). The animals were housed in groups of five rats per cage under controlled laboratory conditions (temperature $20 \pm 2{ }^{\circ} \mathrm{C}$, relative air humidity 55-60\%, LD $12: 12$, lights on at $0600 \mathrm{~h}$ ), with free access to standard diet (Altromin 1326) and tap water.

The experimental design consisted of six groups (each with eight animals) as follows:

(1) sham-operated animals/water; survival time after 'bulbectomy': 3 weeks, control;

(2) bulbectomized animals/water, survival time after bulbectomy: 3 weeks;

(3) sham-operated animals/water; survival time after 'bulbectomy': 8 weeks, control;

(4) sham-operated animals/imipramine, survival time after 'bulbectomy': 8 weeks; 


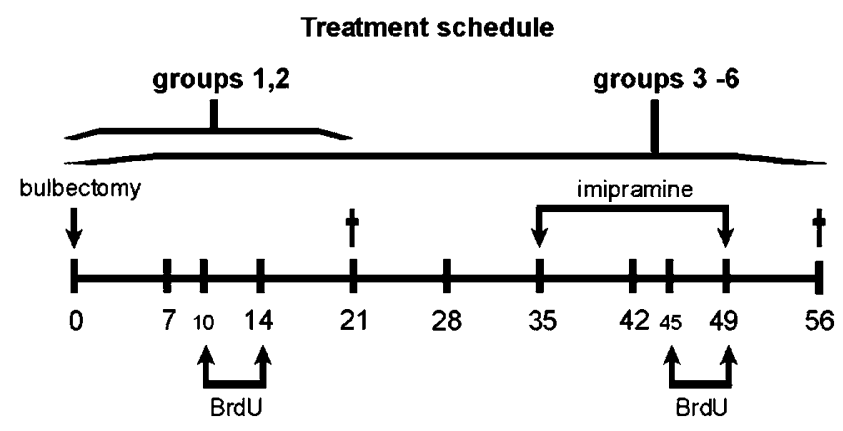

Scheme I

(5) bulbectomized animals/water, survival time after bulbectomy: 8 weeks; and

(6) bulbectomized animals/imipramine, survival time after bulbectomy: 8 weeks.

A diagram of the treatment schedule is given in Scheme 1.

\section{Bulbectomy}

Bilateral bulbectomy was performed as described by O'Connor and Leonard (1986). In brief, 8-week-old rats were anesthetized by pentobarbital ( $40 \mathrm{mg} / \mathrm{kg}$ i.p.), fixed in a stereotactic instrument, and a skin incision was made to expose the skull overlying the bulbs. Holes of $2 \mathrm{~mm}$ diameter were drilled above the bulbs $(6.5 \mathrm{~mm}$ anterior to bregma and $2 \mathrm{~mm}$ on both sides), and both holes were joined to a slotted hole. The olfactory bulbs were cut and completely removed by aspiration using a deflected pipette. The resulting spaces were filled with hemostatic sponges, and the skin was closed by tissue adhesive. Sham-operated rats were treated in the same way, including piercing of the dura mater, but their bulbs were left intact.

\section{Imipramine Treatment}

The subchronic treatment with imipramine (AWD Dresden, Germany) was started 5 weeks after the bulbectomy. The animals received an oral dose of imipramine dissolved in tap water at a concentration of $250 \mathrm{mg} / \mathrm{l}$ (an average of $5 \mathrm{mg} /$ day) for 15 days (6th and 7 th treatment weeks). Control animals received tap water.

\section{Behavioral Study}

Locomotor activity of the rats was investigated using a computerized open field $(100 \times 100 \times 40 \mathrm{~cm})$ (MOTI Test HASOMED, Germany). The frame of the motimeter was equipped with 32 infrared sensor cells in the X-Y level. Lighting in the test room was $600 \mathrm{~lx}$. The activity of each animal was registered for $5 \mathrm{~min}$. Horizontal activity was defined as the distance traveled in $5 \mathrm{~min}$, and it was analyzed in the four experimental groups that had a survival time after bulbectomy of 8 weeks (groups 3-6, two additional animals per group were integrated).

The behavioral study was performed on the 15th day of subchronic treatment with oral imipramine or water.

\section{Cell Proliferation and Characterization Assay}

To assess cell proliferation, an immunofluorescence assay for detection of 5-bromo-2'-deoxy-uridine (BrdU) incorporated into cellular DNA (Roche Diagnostics $\mathrm{GmbH}$, Germany) was used. All animals received daily i.p. injections of $50 \mathrm{mg} / \mathrm{kg}$ BrdU (dissolved in physiological saline) on five consecutive days starting 12 days before they were killed. Imipramine-treated animals were treated with BrdU for the last 5 days of imipramine application. At 7 days after the last BrdU injection, the animals were anesthetized with chloral hydrate, and were transcardially perfused with $200 \mathrm{ml}$ of $0.1 \mathrm{M}$ phosphate-buffered saline (PBS, pH 7.4), followed by $400 \mathrm{ml}$ of $4 \% 0.1 \mathrm{M}$ phosphatebuffered paraformaldehyde (Merck, Darmstadt, Germany, $\mathrm{pH} \mathrm{7.4)}$ at a rate of $15 \mathrm{ml} / \mathrm{min}$. Brains were quickly removed from the cranium, postfixed in the same fixative at $4{ }^{\circ} \mathrm{C}$ overnight, cryoprotected in a solution of $30 \%$ sucrose (Merck) in $0.4 \%$ buffered paraformaldehyde ( $\mathrm{pH} 7.4$ ) for 2 days, and rapidly frozen at $-20^{\circ} \mathrm{C}$ using 2-methylbutane (Roth, Karlsruhe, Germany). Serial sagittal sections $(20 \mu \mathrm{m}$ thick) were cut on a cryostat (Jung Frigocut 2800 E, Leica, Bensheim, Germany), as described in Scheme 2A. Free-floating sections were washed and incubated in $2 \mathrm{M} \mathrm{HCe}$ for $1 \mathrm{~h}$ at $37^{\circ} \mathrm{C}$ for DNA denaturation, and neutralized with $0.1 \mathrm{M}$ borate buffer $(\mathrm{pH} 8.5)$. After washing in PBS, sections were treated in $1 \% \mathrm{H}_{2} \mathrm{O}_{2} \quad(30 \mathrm{~min})$, then blocked with $1 \%$ fetal calf serum (in PBS, $30 \mathrm{~min}$ ), and incubated with a rat monoclonal antibody to BrdU (Oxford Biotechnology Ltd, Oxford, UK; 1:100, in PBS containing $0.3 \%$ Triton $\mathrm{X}-100$ ) for $1 \mathrm{~h}$ at $37^{\circ} \mathrm{C}$. After several rinses in PBS, slices were incubated with the corresponding antibodies: polyclonal rabbit anti-GFAP (Progen, Heidelberg, Germany; 1:50), monoclonal mouse anti-NeuN (Chemicon; 1:100), polyclonal goat anti-doublecortin (DCX, Santa Cruz Biotechnology, Santa Cruz, USA; 1:300), polyclonal rabbit anti-chondroitin sulfate proteoglycan (NG2, Chemicon; 1:500), monoclonal mouse anti-galactocerebrosid (Galac, Chemicon; 1:500), or a monoclonal mouse anti-CD 11b/c (Ox42, Pharmingen, Hamburg, Germany; 1:800) in PBS with $0.3 \%$ Triton X-100 and $1 \%$ normal goat serum overnight at $4{ }^{\circ} \mathrm{C}$ for cell characterization. Following this, slices were washed in PBS $(3 \times 5 \mathrm{~min})$ and incubated overnight with a combination of secondary antibodies (Molecular Probes, Göttingen, Germany; 1:500): goat anti-rat-IgG Alexa Fluor 488/goat anti-rabbit-IgG Alexa Fluor 546 or goat anti-rat-IgG Alexa Fluor 546/goat anti-mouse-IgG Alexa Fluor 488. All sections were further triple-labeled with DAPI (Sigma; $1 \mu \mathrm{g} / \mathrm{ml}$ ) for $10 \mathrm{~min}$ to visualize nuclei, then mounted and examined using a fluorescence microscope (Axiophot, Zeiss) equipped with fluorescein, rhodamine, and DAPI optics. Control reactions (substitution of the primary antisera with $\mathrm{PBS}$ ) yielded negative results (ie no specific immunostaining was seen in these sections).

\section{Assessment of Cell Death}

The technique of terminal deoxynucleotidyl transferasemediated biotinylated UTP nick-end labeling (TUNEL) was used to detect apoptotic DNA fragmentation in the hippocampus, SVZ, RMS, and amygdala. Cryosections were 


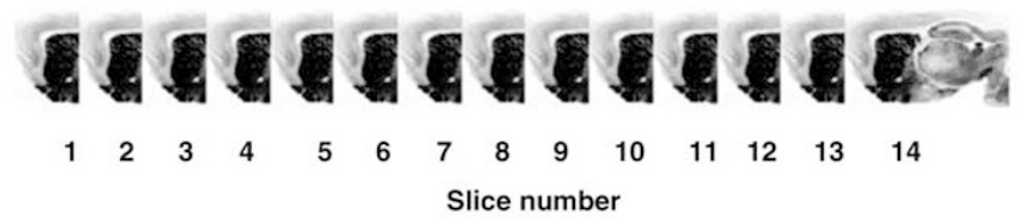

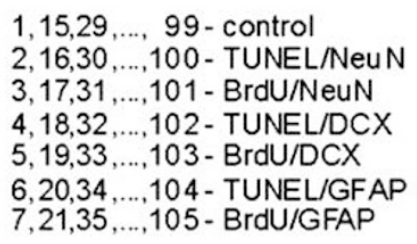

$8,22,36, \ldots, 106$ - TUNEL/galac

$9,23,37, \ldots, 107$ - BrdU/galac

$10,24,38, \ldots, 108$ - TUNEL/NG2

$11,25,39, \ldots, 109$ - BrdU/NG2

$12,26,40, \ldots, 110$ - TUNEL/OX42

$13,27,41, \ldots, 111$ - BrdU/OX42

$14,28,42, \ldots, 112$ - control

b
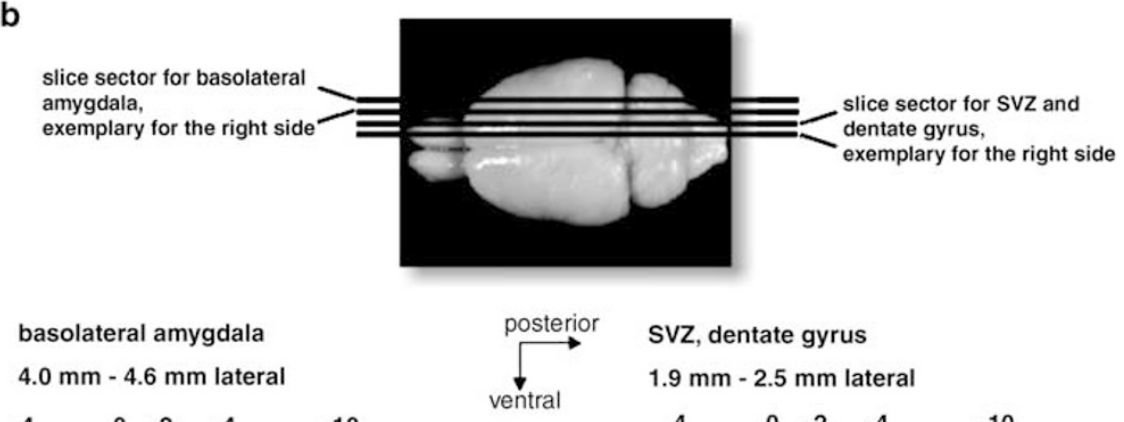

SVZ, dentate gyrus

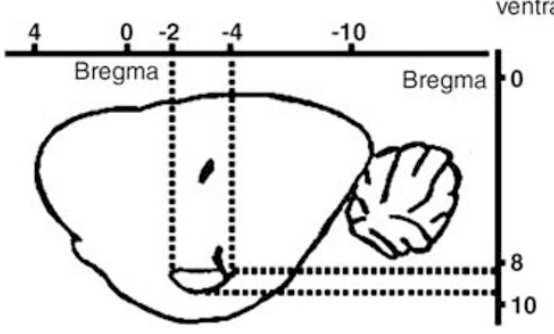

$1.9 \mathrm{~mm}-2.5 \mathrm{~mm}$ lateral

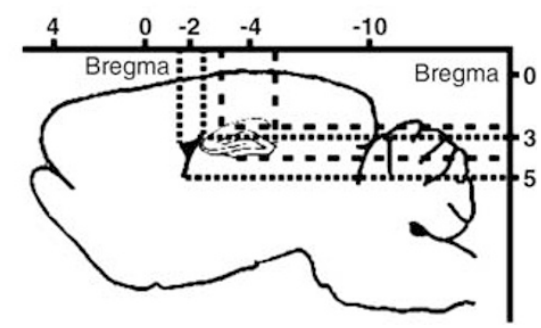

Scheme 2

washed, permeabilized with methanol:chloroform:acetic acid $(66: 33: 1,10 \mathrm{~min})$ and incubated in a humidified box $\left(37^{\circ} \mathrm{C}, 90 \mathrm{~min}\right)$ using $50 \mu \mathrm{l}$ reaction solution: $0.4 \mu \mathrm{l}$ terminal deoxynucleotidyl transferase (TdT, $0.5 \mathrm{U} / \mu \mathrm{l}), 2 \mu \mathrm{l}$ cobalt chloride $(2.5 \mathrm{mM}), 4 \mu \mathrm{l} \mathrm{TdT}$ reaction buffer, $0.8 \mu \mathrm{l}$ biotindUTP (2 nM), and $12.8 \mu \mathrm{l}$ MilliQ (Roche Diagnostics, Germany). The reaction was stopped by washing slices in saline sodium citrate $(3 \times 5 \mathrm{~min})$ and TBS $(2 \times 5 \mathrm{~min})$. The incorporated dig-dUTP was detected using digoxigenin antibodies with the peroxidase-antiperoxidase technique, and visualized with $3,3^{\prime}$-diaminobenzidine using the DAKOLSAB-kit (Dako, Hamburg, Germany). Additionally, all slices were triple-stained with the respective antibodies for cell identification and with DAPI for nuclei labeling as described before.

\section{Statistical Analysis}

To estimate the number of BrdU- and TUNEL-positive cells in the brain regions examined, two independent investigators, blinded to the treatment group, counted the respective stained cell profiles at higher magnification using the optical dissector method, as described elsewhere (Bernstein et al, 1998). Slices were sampled from the respective coordinates according to the rat brain atlas of Paxinos (Paxinos and Watson, 1998): for dentate gyrus, 1.9-2.5 mm lateral, -2.5 to $-4.0 \mathrm{~mm}$ posterior to bregma, $3.0-5.5 \mathrm{~mm}$ ventral to bregma; for SVZ, $1.9-2.5 \mathrm{~mm}$ lateral, -1.5 to $-2.5 \mathrm{~mm}$ posterior to brema, $3.0-5.0 \mathrm{~mm}$ ventral to bregma; for basolateral amygdala, $4.0-4.6 \mathrm{~mm}$ lateral, -2.0 to $-4.0 \mathrm{~mm}$ posterior to bregma, $8.3-9.2 \mathrm{~mm}$ ventral to bregma (Scheme 2B). The actual thickness of the sections was $20 \mu \mathrm{m}$ and two well-defined optical planes within the section were used (distance $16 \mu \mathrm{m}$ ). The marked cells were counted as they came into focus when passing from the upper to the lower optical plane. For the basolateral amygdala, SVZ, and RMS, one counting square was $0.1 \mathrm{~mm}^{2}$, and five such fields per slice were randomly selected and analyzed. For the dentate gyrus, the complete structure per slice was counted. For each animal, region and marker, eight sections were examined using a Zeiss Axiophot with a Plan-Neofluar objective $(\times 40 / 0.75)$. Corresponding digital images were acquired with a digital camera AxioCam MRc (Zeiss). Using the number of cell profiles within the 'counting box' (ie between the two planes of the dissector) and the square of the counting area, it was 
possible to calculate the amount of BrdU-positive and TUNEL-positive cells within the given tissue volume. The data were statistically analyzed using the Friedman test for homogeneity of registered samples, and then using the nonparametric two-tailed $U$-test (Mann and Whitney). Values are expressed as means with standard errors of their men (SEM). Statistical significance was set at $p<0.05$.

\section{RESULTS}

We found that the basal levels of cells incorporating BrdU in the hippocampus and SVZ of sham-operated control animals were consistent with those of previous reports (Kempermann and Gage, 2000; Mandairon et al, 2003; Brown et al, 2003; Yang et al, 2004). In the SVZ, BrdUpositive cells were concentrated in a tight band in the dorsal area (Figure 1a), and in a looser network of single cells in the ventral area. In the hippocampus, BrdU-incorporating cells were typically observed in the subgranular zone, on the border of the granule cell layer and the hilus, as well as within the hilus (Figure 1b). In the basolateral amygdala, only scattered BrdU-labeled cells were detected (Figure 1c).

\section{Olfactory Bulbectomy Influences Neurogenesis in a Region-Specific Manner}

As illustrated in Figure 2, the numbers of BrdU-incorporating cells were significantly decreased (by $\sim 50 \%$ in the SVZ, Figure 1d; and by $\sim 30 \%$ in the hippocampus, Figure 1e) when compared with the respective sham-operated animals. This decrease was detected as early as 3 weeks after bulbectomy. There were no obvious differences in the distribution of BrdU-immunoreactive cells at different longitudinal levels of the dentate gyrus. In the SVZ, the reduction in neurogenesis was more evident with increasing survival time (Figure $2 \mathrm{a} v s \mathrm{~b}$ ). In contrast to the
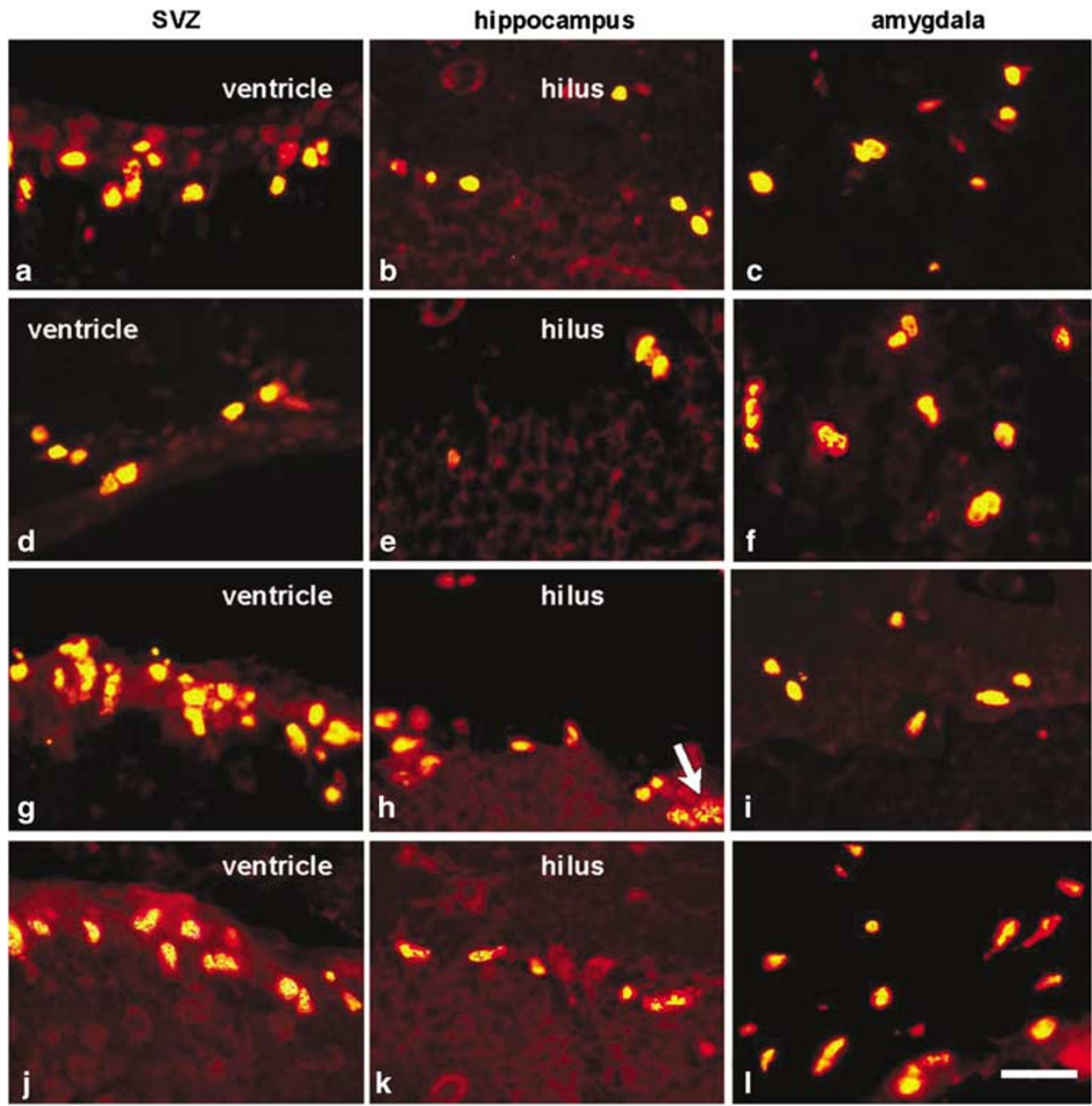

Figure I BrdU labeling of nuclei (yellow dots) of newly formed cells indicates a baseline mitotic activity in the SVZ (a), hippocampus (b), and basolateral amygdala (c) in sham-operated animals. A decrease of BrdU incorporation is seen 8 weeks after bulbectomy in the SVZ (d) and in the hippocampus (e), whereas in the basolateral amygdala ( $f$ ), an increase of mitotic activity is evident. Subchronic imipramine treatment increases cell proliferation in the SVZ (g) as well as in the hippocampus (h), but has no effect in the basolateral amygdala (i). Sometimes, clustering of BrdU-positive nuclei (arrow in h) in the subgranular proliferative zone at the border of the hilus and granule cell layer can be seen. Cell proliferation in the SVZ (j) and in the hippocampus ( $k$ ) was normalized by subchronic imipramine treatment. In the basolateral amygdala, imipramine treatment is ineffective regarding the bulbectomy-induced changes of cell proliferation (I). Scale bar valid for all parts: $100 \mu \mathrm{m}$. 
a

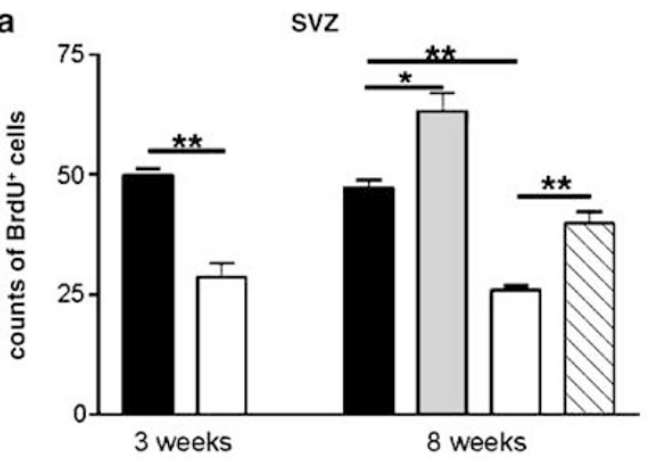

b

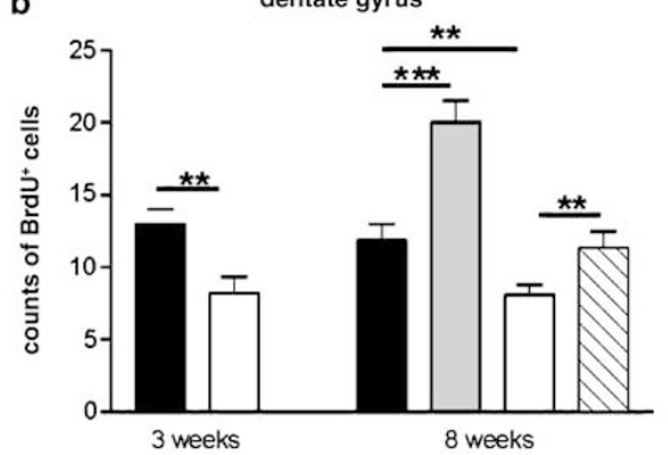

C

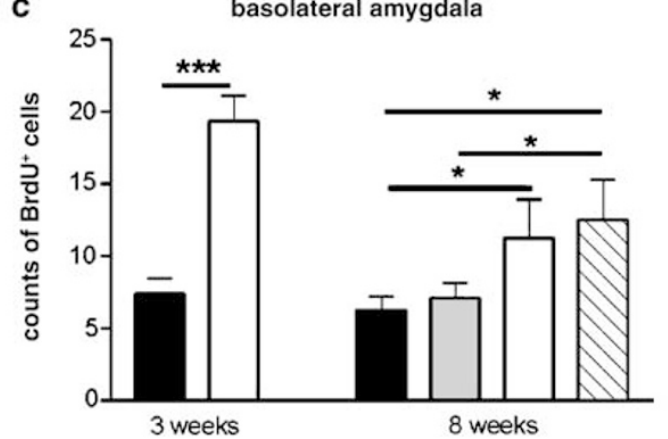

sham operated $+\mathrm{H}_{2} \mathrm{O}$

sham operated + imipramine

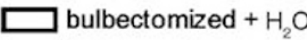

$\square$ bulbectomized + imipramine

Figure 2 Quantitative analysis of ongoing cell proliferation in the dentate gyrus, SVZ, and basolateral amygdala as measured in rats injected with $\mathrm{BrdU}$; comparison of mean numbers ( \pm SEM; related to $0.016 \mu \mathrm{m}^{3}$ for amygdala, SVZ, and RMS; related to the complete structure per slice for dentate gyrus) of BrdU-immunoreactive nuclei in sham-operated animals untreated or treated with imipramine, and bulbectomized rats again untreated or treated with imipramine. (*) Significantly increased number of BrdU-labeled cells analyzed by the nonparametric two-tailed U-test (Mann and Whitney, ${ }^{*} p<0.05$, ${ }^{*} p p<0.005$, $\left.* * * p<0.0005\right)$.

hippocampus and SVZ, neurogenesis in the basolateral amygdala was significantly enhanced (three-fold) by bulbectomy after a survival time of 3 weeks (Figure 2c). Double staining for BrdU and DCX, GFAP, NeuN, galac, NG2, or OX42 revealed that the majority of 'newcomers' in the amygdala were neuronal precursors $(85 \%$ DCX + ), not glial cells (Figure 6a-f). After a survival time of 8 weeks, the number of BrdU-positive cells in this brain region was increased, but to a lesser extent when compared with the amounts after the shorter survival time (Figure 2c).

\section{Subchronic Imipramine Treatment Increases Neurogenesis in the SVZ and Hippocampus, but not in Amygdala}

Treatment with the antidepressant drug imipramine in subchronic doses induced a significant increase in the number of BrdU-labeled nuclei in the SVZ (Figure 1g) and in the hippocampal subgranular zone (Figures $1 \mathrm{~h}, 2 \mathrm{a}$ and $\mathrm{b}$ ) compared with control animals. There was no difference between the left and right hemispheres. Using markers for the neuronal precursors (DCX), mature neurons (NeuN), and glia (GFAP, NG2, galac, OX42), the phenotype of the BrdU-positive cells was determined again by double immunofluorescence labeling. In the SVZ, newly formed cells were predominantly $(>80 \%)$ neuronal precursors based on their cell profile and positive immunostaining for DCX. The remaining cells were distributed as follows: approximately $8 \%$ were NeuN-positive, $4 \%$ expressed GFAP, and $8 \%$ represented a phenotype labeled by the double-staining procedures for oligodendrocytes, synantocytes, or microglia. Throughout the dentate gyrus, the BrdU-labeled cells had normal granule cell morphology, and appeared ovoid or round, with a uniformly stained nucleus. Only a few clusters of newborn cells were observed. The majority of BrdU-labeled cells (75\%) were, again, neuronal precursors expressing DCX; approximately 10\% expressed the NeuN protein and 5\% were labeled for GFAP. The remaining $10 \%$ of cells again represented cell types labeled by the other glia markers. A similar cell-type ratio was observed in the untreated sham-operated groups, indicating that imipramine treatment alone does not affect the differentiation of stem cells into neurons and glia. Cell proliferation of the basolateral amygdala remained unaltered by imipramine treatment (Figures $1 \mathrm{i}$ and $2 \mathrm{c}$ ).

\section{Influence of Subchronic Imipramine Treatment on Bulbectomy-Changed Cell Proliferation}

The reduction of cell proliferation in the SVZ and hippocampus assessed 8 weeks after bulbectomy was normalized by imipramine applied 5 weeks after bulbectomy, a time when depression-like disturbances were fully developed (Figures $1 \mathrm{j}, \mathrm{k}$ and $2 \mathrm{a}, \mathrm{b}$ ). After a survival time of 8 weeks, early bulbectomy-induced changes of cell proliferation in the basolateral amygdala were evident, but at a lower level, and again the antidepressant treatment had no effect on cell proliferation (Figures 11 and $2 \mathrm{c}$ ).

\section{Olfactory Bulbectomy and Imipramine Treatment Influence Apoptotic Cell Death in a Region-Specific Manner}

Apoptosis was measured by counting TUNEL-positive cells in the SVZ, RMS, hippocampal subgranular zone, and basolateral amygdala. After the short survival time (3 weeks), bulbectomy did not enhance TUNEL labeling in the areas studied (Figures $3 \mathrm{a}$ and $4 \mathrm{a}-\mathrm{h}$ ). Control counts of TUNEL-positive cells were: $3.04 \pm 0.56$ (mean \pm SEM) in the SVZ, $1.78 \pm 0.48$ in the RMS, $0.91 \pm 0.39$ in the hippocampus, and $3.39 \pm 0.76$ in the basolateral amygdala.

At 8 weeks after bulbectomy, however, the number of TUNEL-labeled cells in the SVZ $(54.4 \pm 8.7$, Figures $3 \mathrm{~b}$ and 
a

apoptotic cell death
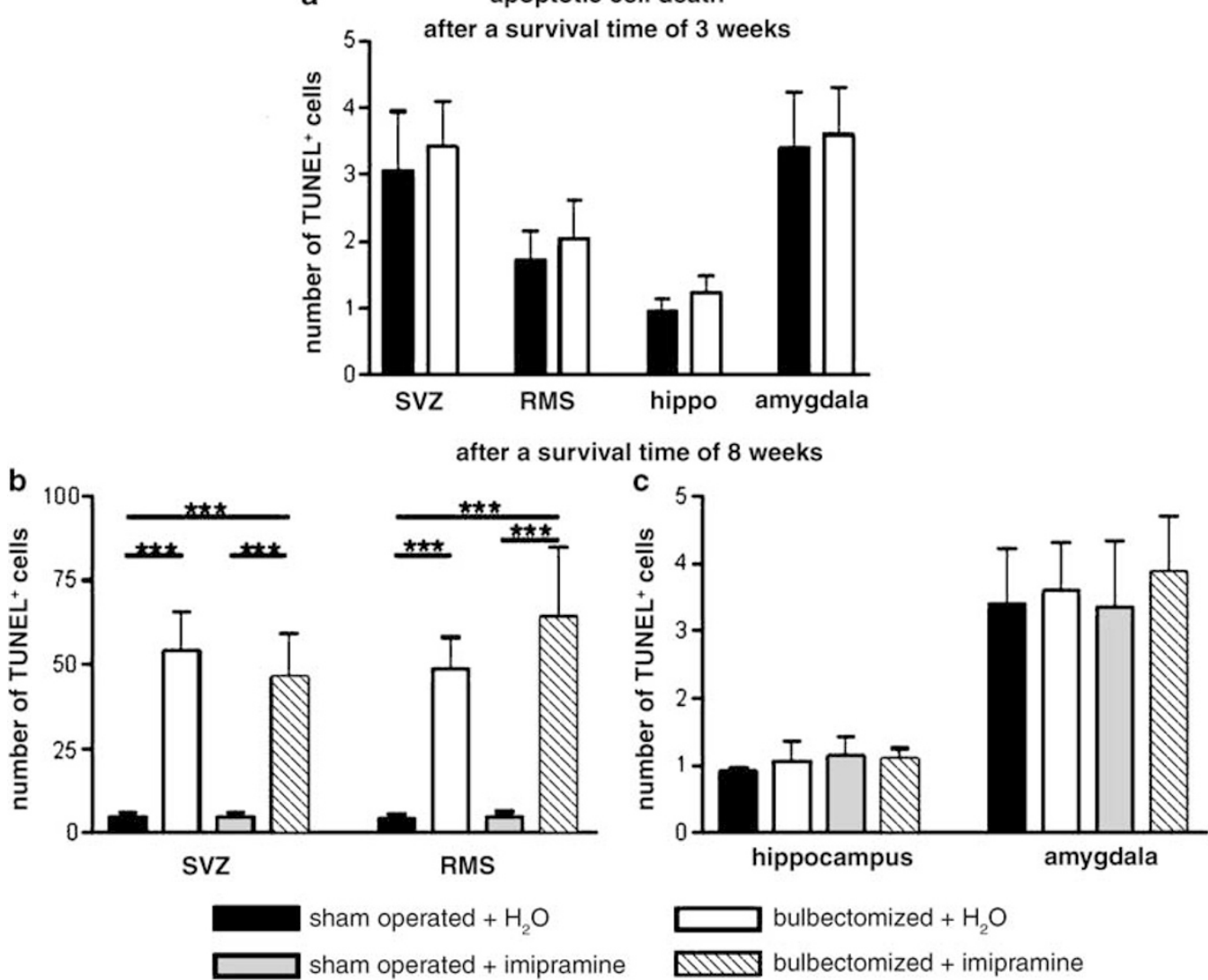

Figure 3 Quantitative analysis of ongoing apoptotic cell death in the SVZ, RMS, hippocampus, and basolateral amygdala as measured in rats exposed to TUNEL staining; comparison of mean numbers $\left( \pm\right.$ SEM; related to $0.016 \mu \mathrm{m}^{3}$ for amygdala, SVZ, and RMS; related to the complete structure per slice for dentate gyrus) of TUNEL-positive nuclei in sham-operated animals untreated or treated with imipramine, and bulbectomized rats again untreated or treated with imipramine. (****) Significantly increased number of TUNEL-stained cells analyzed by the nonparametric two-tailed U-test (Mann and Whitney, $p<0.0005)$

$4 \mathrm{~m})$ and RMS (47.8 \pm 7.9 , Figures $3 \mathrm{~b}$ and $4 \mathrm{n})$ increased dramatically when compared with the respective shamoperated animals (Figure $4 \mathrm{i}$ and $\mathrm{j}$ ), in which only scattered TUNEL-positive cells were found $(3.68 \pm 1.34$ cells in the SVZ and $2.44 \pm 1.76$ cells in the RMS). This enhanced cell death rate was unaffected by imipramine. TUNEL staining revealed similar levels and patterns of dead cells in bulbectomized animals treated with imipramine and in animals submitted to bulbectomy only $(49.8 \pm 6.7$ cells in the SVZ, Figure $4 \mathrm{q} ; 66.7 \pm 12.6$ cells in the RMS, Figures $3 \mathrm{~b}$ and $4 \mathrm{r}$ ).

In contrast to the SVZ and RMS, the cell death rates in the hippocampal subgranular zone and in the basolateral amygdala were not significantly influenced by bulbectomy (Figure 3c). Also, after the survival time of 8 weeks TUNEL labeling was found to be similar to control levels $(1.2 \pm 0.41$ cells in the hippocampus, Figure 4o, and 3.43. \pm 0.96 cells in the amygdala, Figure $4 \mathrm{p}$ ).

Again, treatment with imipramine alone did not show any influence on the apoptotic cell death rate in the brain areas examined, as these had control levels: $2.99 \pm 0.63$ cells in the SVZ, $2.44 \pm 0.52$ cells in the RMS, $1.22 \pm 0.44$ cells in the hippocampus, and $3.26 \pm 0.66$ cells in the amygdala (Figure $4 \mathrm{u}-\mathrm{x}$ ).

The costaining of TUNEL and the respective antibodies for cell identification revealed that the apoptotic cells were neurons (NeuN-positive), neuronal precursors (DCX-positive), oligodendroglial precursors and/or synantocytes (NG2-positive), and oligodendroglial cells (galac-positive; Figure 6g-1).

\section{Behavior}

The normalizing effect of imipramine on behavioral disturbances in bulbectomized rats as demonstrated previously for intraperitoneal application (Grecksch et al, 1997) was reproduced using an oral application schedule. Hyperactivity was found in bulbectomized rats compared with bulbectomy control animals. This hyperactivity was normalized by an oral imipramine dose of $5 \mathrm{mg} /$ day, but the behavior in control rats was not influenced by imipramine (Figure 5).

\section{DISCUSSION}

Here, we report that bulbectomy results in a decrease in cell proliferation in both the hippocampal subgranular zone and the SVZ of adult rats, whereas bulbectomy leads to increased cell genesis in the basolateral amygdala. Importantly, we found that subchronic doses of imipramine are 


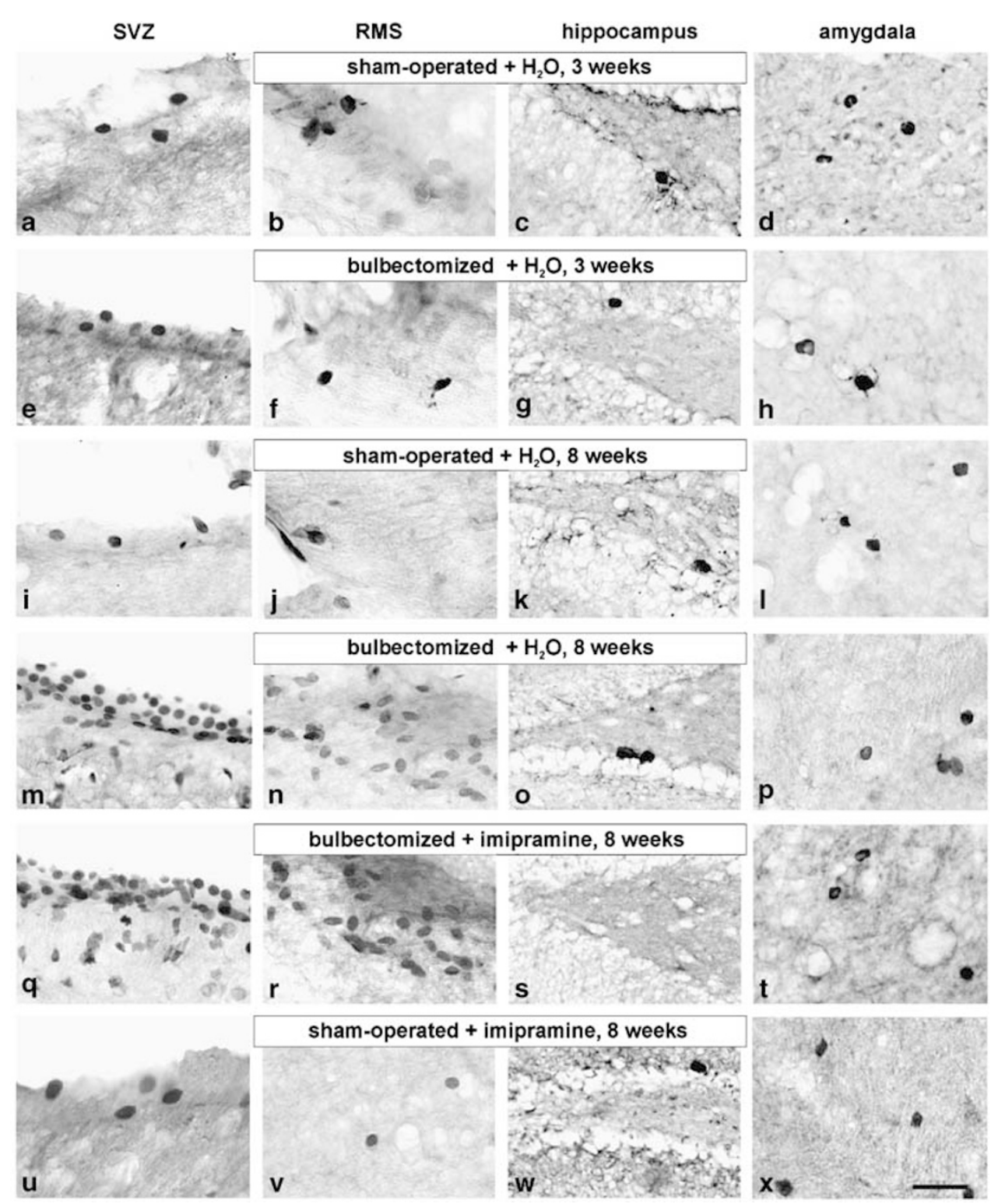

Figure 4 TUNEL staining after a survival time of 2 weeks depicting a baseline of apoptotic cell nuclei in sham-operated control animals (a-d), and an unchanged number of TUNEL-positive nuclei in bulbectomized animals (e-h). At 8 weeks after bulbectomy, a dramatic increase in TUNEL-stained nuclei is evident in the SVZ ( $m$ vs i) and in the RMS ( $n$ vs j), whereas the apoptotic cell death rate in the hippocampus (o vs k) and basolateral amygdala ( $p$ vs I) are unchanged. Imipramine is not able to reduce bulbectomy-induced apoptosis in SVZ (q) or RMS ( $r$ ), and has no effect in the hippocampus ( $\mathrm{s}$ ) or amygdala ( $\mathrm{t}$ ) of bulbectomized animals. Moreover, in all the areas studied, imipramine alone is not effective $(u-x)$. Scale bar valid for all parts: $100 \mu \mathrm{m}$.

able to reverse bulbectomy-induced inhibition of cell proliferation in the hippocampus and SVZ.

Our findings regarding the hippocampus are consistent with those of recent studies that report a profound effect of dentate gyrus neurogenesis in different models of depression and in different experimental animals, including intruder stress in marmosets (Gould et al, 1998), psychosocial stress in tree shrews (Czeh et al, 2001; van der Hart et al, 2002), and, in rodents, social defeat (Czeh et al, 2002), footshock stress (Malberg and Duman, 2003), and chronic mild stress (Alonso et al, 2004). In addition, the decreased neurogenesis induced by inescapable stress correlates with behavioral despair several days after exposure to stress in the learned helplessness model of depression (Malberg and Duman, 2003). Also, rats in which neurogenesis was disrupted during the late gestational have deficits in a reversal-learning paradigm of the Morris water maze and in object recognition; they also exhibit perseveration in the Porsolt forced swimming test. Additionally, deficient associative learning in the acquisition of an active avoidance paradigm, and deficits in latent inhibition, have been demonstrated (Flagstad et al, 2005).

We substantiated the validity of a previously demonstrated depression model, showing that bulbectomy leads to depression-like behavioral deficits, such as a reduced learning performance (Grecksch et al, 1997) and different forms of aggression (Rutkoski et al, 2002). The correlation between decreased cell proliferation and depression-like behavioral abnormalities at a point in time well after exposure to the respective inductor indicates that the 


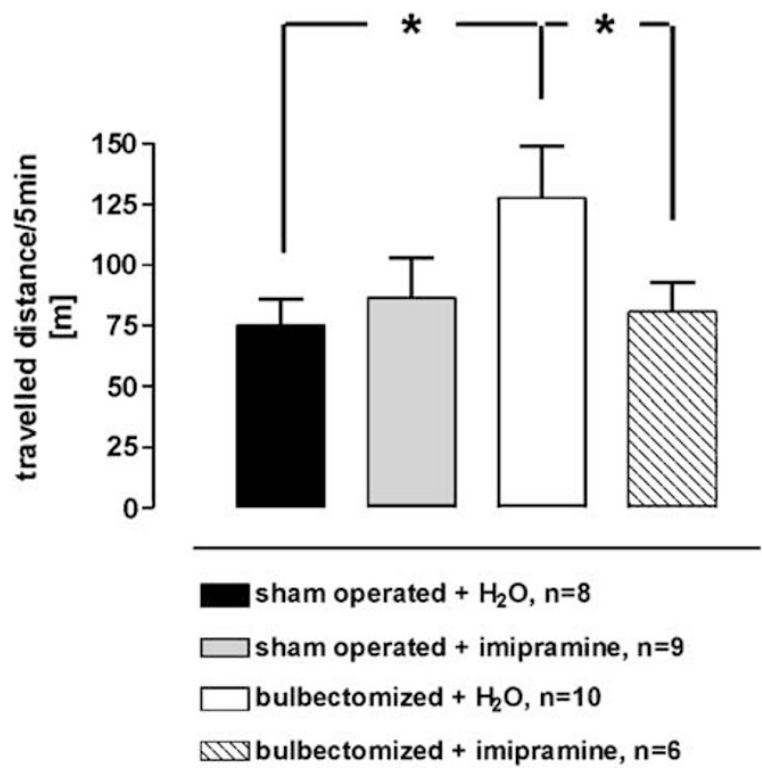

Figure 5 Quantitative analysis of locomotor activity analyzed by the nonparametric H-test (Kruskal-Wallis) and post hoc by the U-test. Statistical significance (*) was set at $p<0.05$.

reduction of neurogenesis is not simply due to psychological or mechanical stress; this was interpreted by Duman (2004) as possible evidence for a correlation between abolished neurogenesis and depression-like behavior.

In the published literature, there is a great consensus that the hippocampus may contribute to certain symptoms of depression, such as problems with declarative learning and memory (for a review see: Sheline et al, 2002; Duman, 2004). Also, virtually all of the participants in this debate agree that failure of adult hippocampal neurogenesis could help to explain the cognitive deficits of depression (Jacobs, 2002; Kempermann, 2002; Kempermann and Kronenberg, 2003). These authors have proposed that a reduced ability of the hippocampus to cope with novelty and complexity leads to inadequate information processing at the interface between systems involved in learning and affecting regulation, thus constituting a possible link between adult neurogenesis and depression. The insufficient reaction of patients to the challenges of the outside world could overwhelm the system and result in a hippocampal 'shut down' (Kempermann and Kronenberg, 2003). In addition, the hippocampus provides inputs to other brain regions, including the prefrontal cortex, cingulate cortex, and amygdala, which contribute substantially to altered mood and emotion in depression (Duman, 2004).

Moreover, the olfactory bulbs project fibers widely to the olfactory cortex, including the olfactory tubercle, amygdala, and entorhinal cortex. Thus, bulbectomy affected the amygdala, which is also related to depression (Rutkoski et al, 2002; Sapolsky, 2004). However, in contrast to the hippocampus, an increased cell proliferation was noticed in this area. Initially, these results seem to negate the postulated link between depression-like symptoms and impaired neurogenesis. A psychic impairment can result not only from reduced but also from enhanced cell production. Several lines of evidence implicate newly generated neurons in structural and functional network abnormalities in the brain of adult rodents (reviewed by Parent and Lowenstein, 2002). These abnormalities include aberrant mossy fiber reorganization, persistence of immature granule cells, for example, basal dendrites, and the abnormal migration of newborn neurons. Thus, increased neurogenesis might be relevant also to pathogenesis of cognitive disorders.

Moreover, our findings raise the question as to how one and the same procedure, bulbectomy, can induce a decrease of cell proliferation in hippocampus and an increase in amygdala, both of which are areas of the limbic system. By Ho et al (2001) it was shown that bulbectomy reduces the NMDA receptor density in the amygdala. Together with the findings that a blockade of NMDA receptors increases cell proliferation in the rat brain (Gould et al, 1997; Nacher et al, 2003), it may explain the enhanced cell proliferation in the amygdala. The hippocampal NMDA receptor system, on the other hand, was not influenced by bulbectomy (Ho et al, 2001), thus explaining the seen differences in bulbectomyinduced cell proliferation in the dentate gyrus when compared with the amygdala. The opposite influence of bulbectomy on cell proliferation in the hippocampus $v s$ the amygdala is in agreement with the findings of Vyas et al (2002), who demonstrated that chronic stress can cause contrasting patterns of dendritic remodeling in neurons of the amygdala and hippocampus.

The remaining question is that regarding a link between depression-like symptoms and impaired cell proliferation in the SVZ of bulbectomized rats. The SVZ is the major neurogenic area of the postnatal and adult brain, and the majority of the newly formed cells migrate into the olfactory bulb via the well-characterized RMS. However, a substantial proportion of SVZ-derived progenitors migrate in a ventral migratory mass across the nucleus accumbens into the cortical and subcortical structure (de Marchis et al, 2004). A reduced supply of cells from the SVZ to the cortical structures, however, is thought to be one of the pathogenetic factors of major psychiatric disorders (for a review see: Byrum et al, 1999; Marin and Rubenstein, 2003). Thus, bulbectomy-induced disturbances of the SVZ neurogenesis might be relevant also to pathogenesis of mood disorders.

Our results concerning normalization of cell proliferation by imipramine together with the imipramine-induced restoration of the deficient learning performance of bulbectomized rats (Grecksch et al, 1997) add to the existing published literature, which demonstrate that antidepressants reverse the decrease in cell proliferation in different stress models of depression (Czeh et al, 2001; van der Hart et al, 2002; Malberg and Duman, 2003; Alonso et al, 2004). Antidepressants may act by restoring altered rates of cell birth or death. According to a relevant paper of Lucassen et al (2004), treatment with the antidepressant tianeptine reduces apoptosis in hippocampal subfields and temporal cortex. So, it seems possible that the lack of apoptosis in the hippocampus and amygdala, as demonstrated herein, is a result of imipramine treatment rather than of the late evaluation point. On the other hand, in SVZ and RMS, we were able to demonstrate enhanced apoptotic cell death rates 8 weeks after bulbectomy, and they were not influenced by imipramine treatment. These differences suggest a region-specific effect of the antidepressant treatment, which was also found in the paper 


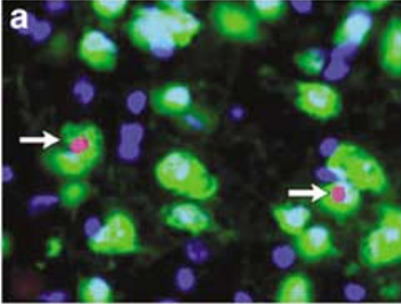

BrdU NeuN DAPI

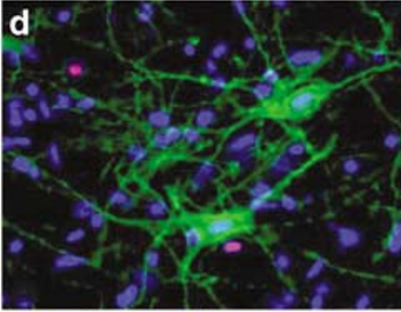

BrdU Galac DAPI

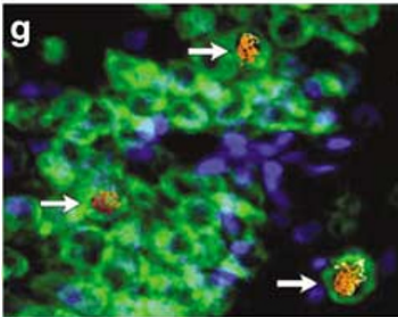

TUNEL NeUN DAPI

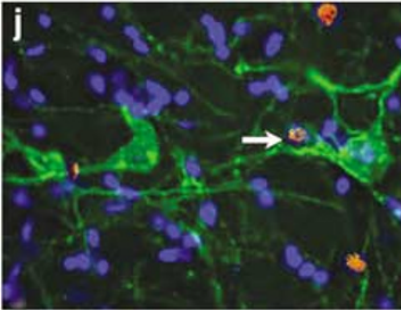

TUNEL Galac DAPI

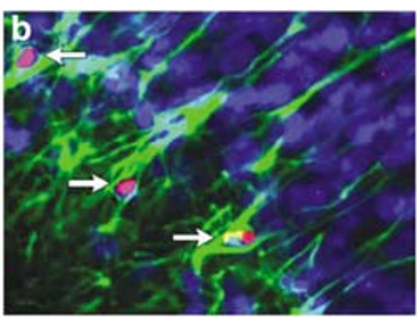

BrdU DCX DAPI

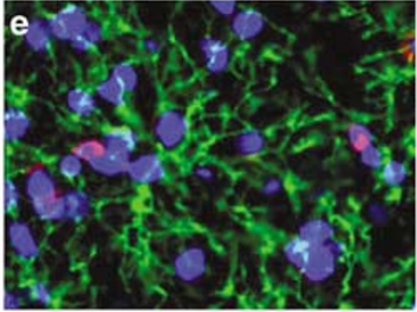

BrdU NG2 DAPI

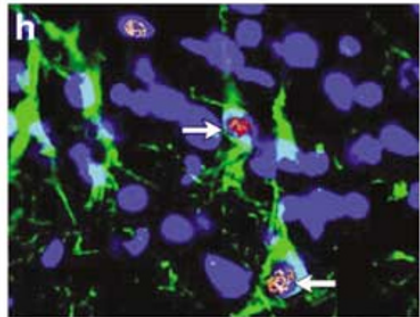

TUNEL DCX DAPI

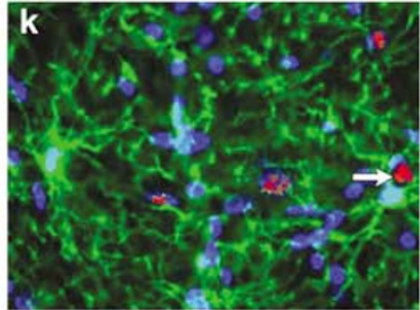

TUNEL NG2 DAPI

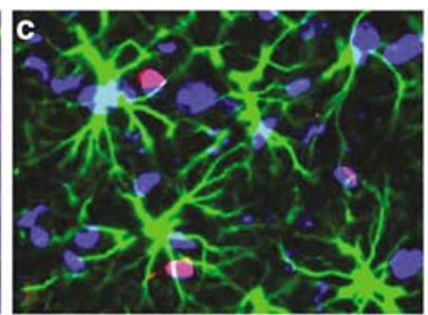

BrdU GFAP DAPI

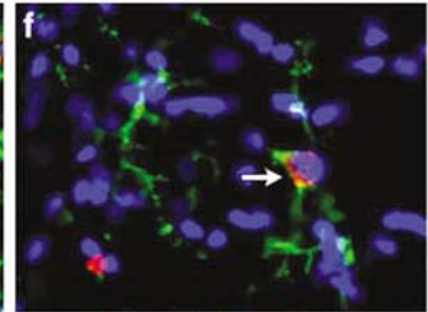

BrdU Ox42 DAPI

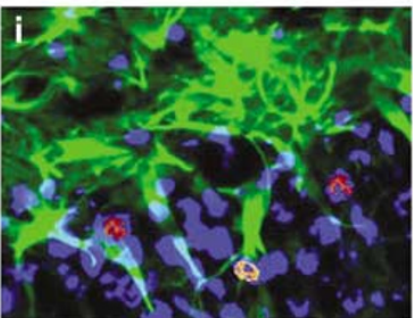

TUNEL GFAP DAPI

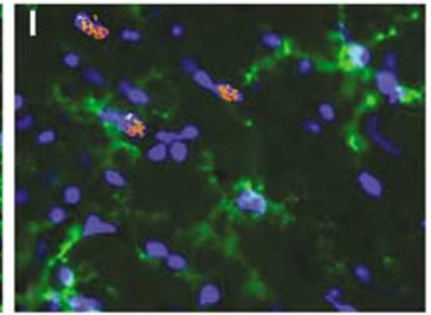

TUNEL OX42 DAPI

Figure 6 Immunofluorescent double-labeling of BrdU-positive cells. (a) Coexpression with the neuronal marker NeuN (arrows, here in the basolateral amygdala), and (b) with the neuronal precursor marker DCX (arrows, in the dentate gyrus) indicates a neuronal development of imipramine induced newly formed cells. (c) A colabeling with the astroglial marker GFAP (hilus), (d) the oligodendroglial marker galac (amygdala), or (e) with NG2, a marker for oligodendroglial precursors/synatocytes, was hardly detectable. (f) Some of the BrdU-positive cells coexpressed OX42, indicating a microglia proliferation in the amygdala after bulbectomy. The entirety of cells was demonstrated by DAPI staining. Immunofluorescent double-labeling of TUNEL-positive cells 8 weeks after bulbectomy. (g) Most of the apoptotic cells were NeuN-positive indicating their neuronal nature (hippocampus). (h) DCX expressing neuronal precursors, (j) galac expressing oligodendroglial cells as well as their precursors (NG2-positive, k) were also affected by apoptosis (amygdala), whereas astroglia (GFAP-positive, i) seemed to be unaffected.

mentioned above. Tianeptine, highly effective in the hippocampus and temporal cortex, had no effect in the Ammon's Horn. Moreover, the differences in time kinetics between apoptosis and BrdU incorporation, which was seen already 3 weeks after bulbectomy, suggest indirect or delayed apoptotic cell death mechanisms. Delayed apoptosis is an accepted phenomenon in the nervous system. From stroke patients, it is known that the structural lesion solidifies over weeks recruiting additional parts of the brain into infarction (Dirnagl et al, 1999); and for peripheral nerve injury or ventral root avulsion, an injury-induced progressive death of motor neurons was shown (Hoang et al, 2003). To clarify the nature of apoptotic cell death in our paradigm, further experiments with different time windows will be essential.

In conclusion, our experiments revealed that bulbectomy has a blocking effect on cell proliferation in the hippocampus and SVZ, and a stimulating effect in the amygdala. The antidepressant imipramine normalizes neurogenesis in the hippocampus and SVZ only, but not in the amygdala. Both, increased and decreased cell proliferation, may be causally related to depression: a reduced number of neurons in the hippocampus directly contributes to aspects of depression-like declarative learning and memory, and an incorrect integration of newly formed cells into the wellestablished orchestra of adult cells is also considered to 
induce a functional black out leading to depression-like disorders.

\section{ACKNOWLEDGEMENTS}

The professional technical assistance of Leona Bück, Gabriele Schulze, Petra Dehmel, and Beate Reuter is gratefully acknowledged. We thank Ms Ann Shakespeare for revising the English. This study was supported by the Bundesministerium für Bildung und Forschung of Germany (NBL3, PFG 1/4) and the Hertie-Stiftung (1.01.1/03/011).

\section{REFERENCES}

Aggleton JP (1993). The contribution of the amygdala to normal and abnormal emotional states. Trends Neurosci 16: 328-333.

Alonso R, Griebel G, Pavone G, Stemmelin J, Le Fur G, Soubie P (2004). Blockade of CRF (1) or V (1b) receptors reverses stressinduced suppression of neurogenesis in a mouse model of depression. Mol Psychiatry 9: 278-286.

Bernstein H-G, Stanarius A, Baumann B, Henning H, Krell D, Danos P et al (1998). Nitric oxide synthase-containing neurons in the human hypothalamus: reduced number of immunoreactive cells in the paraventricular nucleus of depressive patients and schizophrenics. Neuroscience 83: 867-875.

Bouix S, Pruessner JC, Louis Collins D, Siddiqi K (2005). Hippocampal shape analysis using medial surface. Neuroimage 25: 1077-1089.

Brown JP, Couillard-Despres S, Cooper-Kuhn CM, Winkler J, Aigner L, Kuhn HG (2003). Transient expression of doublecortin during adult neurogenesis. J Comp Neurol 467: 1-10.

Byrum CE, Ahearn EP, Krishnan KR (1999). A neuroanatomic model for depression. Prog Neuropsychopharmacol Biol Psychiatry 23: 175-193.

Castren E (2004). Neurotrophic effects of antidepressant drugs. Curr Opin Pharmacol 4: 58-64.

Czeh B, Michaelis T, Watanabe T, Frahm J, de Biurrun G, van Kampen $\mathrm{M}$ et al (2001). Stress-induced changes in cerebral metabolism, hippocampal volume, and cell proliferation are prevented by antidepressant treatment with tianepine. Proc Nat Acad Sci USA 98: 12796-12801.

Czeh B, Welt T, Fischer AK, Erhardt A, Schmitt W, Müller MB et al (2002). Chronic psychosocial stress and concomitant repetitive transcranial magnetic stimulation: Effects on stress hormone levels and adult hippocampal neurogenesis. Biol Psychiatry 52: 1047-1056.

De Marchis S, Fasolo A, Puche AC (2004). Subventricular zonederived neuronal progenitors migrate into subcortical forebrain of postnatal mice. J Comp Neurol 476: 290-300.

Dirnagl U, Iadecola C, Moskovitz MA (1999). Pathobiology of ischaemic stroke: an integrative view. TINS 22: 391-397.

Drevets WC (2000). Neuroimaging studies of mood disorders. Biol Psychiatry 48: 813-829.

Duman RS (2004). Depression: a case of neuronal life and death? Biol Psychiatry 56: 140-145.

Flagstad P, Glenthoj BY, Didriksen M (2005). Cognitive deficits caused by late gestational disruption of neurogenesis in rats: a preclinical model of schizophrenia. Neuropsychopharmacology 30: $250-260$.

Gould E, McEwen BS, Tanapat P, Galea LA, Fuchs E (1997). Neurogenesis in the dendate gyrus of the adult tree shrew is regulated by psychosocial stress and NMDA receptor activation. J Neurosci 17: 2492-2498.

Gould E, Tanapat P, McEwen BS, Flugge G, Fuchs E (1998). Proliferation of granule cell precursors in the dentate gyrus of adult monkeys is diminished by stress. Proc Natl Acad Sci USA 95: 3168-3171.

Grecksch G, Zhou D, Franke C, Schröder U, Sabel B, Becker A et al (1997). Influence of olfactory bulbectomy and subsequent imipramine treatment on 5-hydroxytryptaminergic presynapses in the rat frontal cortex: behavioural correlates. $\mathrm{Br} J$ Pharmacol 122: $1725-1731$.

Gritti A, Bonfanti L, Doetsch F, Caille I, Alvarez-Buylla A, Lim DA et al (2002). Multipotent neural stem cells reside into the rostral extension and olfactory bulb of adult rodents. J Neurosci 22: 437-445.

Hastings NB, Gould E (1999). Rapid extension of axons into the CA3 region by adult-generated granule cells. J Comp Neurol 413: 146-154.

Henn FA, Vollmayr B (2004a). Neurogenesis and depression: etiology or epiphenomenon? Biol Psychiatry 56: 146-150.

Henn FA, Vollmayr B (2004b). Basic pathophysiological mechanisms in depression: what are they and how might they affect the course of illness? Pharmacopsychiatry 37: 152-156.

Ho YJ, Liu TM, Tai MY, Wen ZH, Chow RSS, Tsai YF et al (2001). Effects of olfactory bulbectomy on NMDA receptor density in the rat brain: $[\mathrm{HH}] \mathrm{MK}-801$ binding assay. Brain Res 900: 214-218.

Hoang TX, Nieto JH, Tillakaratne NJ, Havton LA (2003). Autonomic and motor neuron death is progressive and parallel in a lumbosacral ventral root avulsion model of cauda equina injury. J Comp Neurol 467: 477-486.

Ishii K, Sasaki H, Kono AK, Miyamoto N, Fukuda T, Mori E (2005). Comparison of gray matter and metabolic reduction in mild Alzheimer's disease using FDG-PET and voxel-based morphometric MR studies. Eur J Nucl Med Mol Imaging 31: 959-963.

Jacobs BL (2002). Adult brain neurogenesis and depression. Brain Behav and Immunity 16: 602-609.

Keilhoff G, Bernstein HG, Becker A, Grecksch G, Wolf G (2004). Increased neurogenesis in a ketamine-model of schizophrenia. Biol Psychiatry 56: 317-322.

Kelly JP, Wrynn AS, Leonard BE (1997). The olfactory bulbectomized rat as a model of depression: an update. Pharmacol Ther 74: $299-316$.

Kempermann G (2002). Regulation of adult hippocampal neurogenesis - implications for novel theories of major depression. Bipolar Disord 4: 17-33.

Kempermann G, Gage FH (2000). Neurogenesis in the adult hippocampus. Novartis Found Symp 231: 220-241.

Kempermann G, Kronenberg G (2003). Depressed new neurons-adult hippocampal neurogenesis and a cellular plasticity hypothesis of major depression. Biol Psychiatry 54: 499-503.

Ketter TA, Kimbrell TA, George MS, Dunn RT, Speer AM, Benson BE et al (2001). Effects of mood and subtype on cerebral glucose metabolism in treatment-resistant bipolar disorder. Biol Psychiatry 49: 97-109.

Kirschenbaum B, Doetsch F, Lois C, Alvarez-Buylla A (1999). Adult subventricular zone neuronal precursors continue to proliferate and migrate in the absence of the olfactory bulb. J Neurosci 19: 2171-2180.

Koschack J, Irle E (2005). Small hippocampal size in cognitively normal subjects with coronary artery disease. Neurobiol Aging 26: $865-871$.

Lucassen PJ, Fuchs E, Czeh B (2004). Antidepressant treatment with tianeptine reduces apoptosis in the hippocampal dentate gyrus and temporal cortex. Biol Psychiatry 55: 789-796.

Lucassen PJ, Muller MB, Holsboer F, Bauer J, Holtrop A, Wouda J et al (2001). Hippocampal apoptosis in major depression is a minor event and absent from subareas at risk for glucocorticoid overexposure. Am J Pathol 158: 453-468.

Malberg J (2004). Implication of adult hippocampal neurogenesis in antidepressant action. J Psychiatry Neurosci 29: 196-205. 
Malberg J, Duman R (2003). Cell proliferation in adult hippocampus is decreased by inescapable stress: reversal by fluoxetine treatment. Neuropsychopharmacology 28: 1562-1571.

Malberg JE, Eisch AJ, Nestler EJ, Duman RS (2000). Chronic antidepressant treatment increases neurogenesis in adult rat hippocampus. J Neurosci 20: 9104-9110.

Mandairon N, Jourdan F, Didier A (2003). Deprivation of sensory inputs to the olfactory bulb up-regulates cell death and proliferation in the subventricular zone of adult mice. Neuroscience 119: 507-516.

Marin O, Rubenstein JL (2003). Cell migration in the forebrain. Annu Rev Neurosci 26: 441-483.

Muller MB, Lucassen PJ, Yassouridis A, Hoogendijk WJ, Holsboer F, Swaab DF (2001). Neither major depression nor glucocorticoid treatment affects the cellular integrity of the human hippocampus. Eur J Neurosci 14: 1603-1612.

Nacher J, Alonso-Llosa G, Rosell DR, McEwan BS (2003). NMDA receptor antagonist treatment increases the production of new neurons in the aged rat hippocampus. Neurobiol Aging 24: 273-284.

O'Connor WT, Leonard BE (1986). Effect of chronic administration of the 6-aza analogue of mianserin (Org.3770) and its enantiomers on behaviour and changes in noradrenaline metabolism of olfactory bulbectomized rats in the 'open field' apparatus. Neuropharmacology 25: 267-270.

Parent JM, Lowenstein DH (2002). Seizure-induced neurogenesis: are more new neurons good for an adult brain? Prog Brain Res 135: 121-131.

Paxinos G, Watson C (1998). The Rat Brain in Stereotaxic Coordinates. Academic Press: San Diego, CA.

Richardson JS, Tiong AHK (1999). Amygdaloid and hippocampal $\beta$-adrenoreceptors in the olfactory bulbectomy syndrome: effects of desipramine. Ann NY Acad Sci 877: 764-767.

Rutkoski NJ, Lerant AA, Nolte CM, Westberry J, Levenson CW (2002). Regulation of neuropeptide $\mathrm{Y}$ in the rat amygdala following unilateral olfactory bulbectomy. Brain Res 951: 69-76.

Sapolsky RM (2004). Is impaired neurogenesis relevant to the affective symptoms of depression? Biol Psychiatry 56: 137-139.

Schaffer DV, Gage F (2004). Neurogenesis and neuroadaptation. Neuromol Med 5: 1-9.
Sheline YI, Mittler L, Mintun MA (2002). The hippocampus and depression. Eur Psychiatry 3: 300-305.

Song C, Leonard BE (2005). The olfactory bulbectomized rat as model of depression. Neurosci Biobehav Rev 29: 627-647.

Stockmeier CA, Mahajan GJ, Konick LC, Overholser JC, Jurjus GJ, Meltzer HY et al (2004). Cellular changes in the postmortem hippocampus in major depression. Biol Psychiatry 56: 640-650.

Van der Hart M, Czeh B, de Biurrun G, Michaelis T, Watanabe T, Natt $\mathrm{O}$ et al (2002). Substance $\mathrm{P}$ receptor antagonist and cloipramine prevent stress-induced alterations in cerebral metabolism, cytogenesis in the dentate gyrus and hippocampal volume. Mol Psychiatry 7: 933-941.

van Praag H, Kempermann G, Gage FH (2002). Running increases cell proliferation and neurogenesis in the adult mouse dentate gyrus. Nat Neurosci 2: 266-270.

Vyas A, Mitra R, Shankaranarayana Rao BS, Chattarji S (2002). Chronic stress induces contrasting patterns of dendritic remodelling in hippocampal and amygdaloid neurons. J Neurosci 22: 6810-6818.

Watanabe A, Tohyama Y, Nguyen KQ, Hasegawa S, Debonnel G, Dicsic M (2003). Regional brain serotonin synthesis is increased in the olfactory bulbectomy rat model of depression: an autoradiograhic study. J Neurochem 85: 469-475.

Wrynn AS, Sebens JB, Koh T, Leonard BE, Korf J (2000). Prolonged c-Jun expression in the basolateral amygdala following bulbectomy: possible implications for antidepressant activity and time of onset. Mol Brain Res 76: 7-17.

Yang HKC, Sundholm-Peters NL, Goings GE, Walker AS, Hyland K, Szele FG (2004). Distribution of doublecortin expressing cells near the lateral ventricles in the adult mouse brain. J Neurosci Res 76: 282-295.

Zerlin M, Milosevic A, Goldman JE (2004). Glial progenitors of the neonatal subventricular zone differentiate asynchronously, leading to spatial dispersion of glial clones and to the persistence of immature glia in the adult mammalian CNS. Dev Biol 270: 200-213.

Zhou D, Grecksch G, Becker A, Frank C, Pilz J, Huether G (1998). Serotonergic hyperinnervation of the frontal cortex in an animal model of depression, the bulbectomized rat. J Neurosci Res 54: 109-116. 